\title{
Elicitation of aggression by food deprivation in olfactory bulbectomized male mice
}

\author{
MICHAEL B. FORTUNA \\ Rutgers, The State University, New Brunswick, New Jersey 08903
}

\begin{abstract}
Two experiments were conducted in order to examine the necessary conditions for the elicitation of competitive aggression in olfactory bulbectomized male mice. Experiment 1 compared the fighting produced among pairs of bulbectomized males under either food deprivation or ad-lib feeding, with and without the presence of a food-pellet/competition-eliciting stimulus. Animals fought when food-deprived but not when sated. The presence of a food pellet was not necessary for the promotion of aggression. Experiment 2 sought to remove the condition of isolation in pretest housing. However, when bulbectomized males, housed in pairs, were placed upon a food-deprivation schedule, one member was inevitably cannibalized. Identically treated controls died before exhibiting any cases of cannibalism. These findings indicate that the condition of food deprivation is sufficient to reinstate intraspecific aggression in bulbectomized male mice, as well as combine with the effects of bulbectomy to promote normally inhibited cannibalism.
\end{abstract}

Bilateral removal of the olfactory bulbs of adult male mice has been shown to totally eliminate spontaneous intraspecific aggressive behavior (Denenberg, Gaulin-Kremer, Gandelman, \& Zarrow, 1973; Ropartz, 1968). Bulbectomized male mice will not initiate attack upon an intact adult male, nor will they assume a submissive posture or attempt to escape from the aggressor. These findings were originally interpreted with respect to the elimination of the ability to discern an aggression-promoting pheromone. The existence of this male pheromone has been well documented (Archer, 1968; Conner, 1972; Mugford \& Nowell, 1970, 1971).

In support of this interpretation are data showing that temporary odor masking of both members of a pair of male mice produce an increase in the latency to exhibit attack behavior as well as a decrease in the number of pairs of animals that fight (Fortuna \& Gandelman, 1972; Ropartz, 1968). However, by utilizing zinc sulfate for peripherally inducing anosmia, Edwards, Thompson, and Burge (1972) have clearly demonstrated that the perception of pheromonal stimuli is not a necessary condition for the elicitation of intramale spontaneous aggression. It would appear that agonistic behavior in mice is under multisensory control. The question still remains, Can spontaneous or other types of aggression be demonstrated in male mice lacking the significant neural structures of the olfactory bulbs?

Rowe and Edwards (1971) have reported that

The author is presently at Department of Psychology, University of Denver, Denver, Colorado 80208. The author is indebted to Drs. R. Gandelman and J. A. Trowill for their support and constructive criticism. bulbectomized mice will, indeed, exhibit fighting behavior. Specifically, fighting in bulbectomized male mice was elicited by placing both members of a pair upon a restricted feeding schedule and then introducing a small piece of food into their cage. The resultant fighting behavior has been termed "competitive aggression." However, the circumstances surrounding the bulbectomized animals' aggression were not examined in detail. Data from an important control group (e.g., hungry bulbectomized males without food pellet presentation) was not reported. Without such observations, it is not possible to determine the critical factor(s) for the elicitation of the fighting. Is the food pellet coupled with hunger necessary, or is hunger alone sufficient? The following experiments investigate, in greater detail, competitive aggression among bulbectomized male mice.

\section{EXPERIMENT 1}

\section{Method \\ Thirty-two 60-80-day-old Rockland-Swiss male mice were housed singly in $28 \times 18 \times 13 \mathrm{~cm}$ translucent cages, the floors of which were covered with pine shavings. They were maintained on a 12:12-h light-dark schedule with lights on at 6:00 a.m. All animals underwent bilateral olfactory bulb removal. This was performed under ether anesthesia. A 2-mm hole was trephined in the skull above the bulbs, which then were removed by aspira- tion. Gelfoam was inserted into the space left by the removed tissue and the wound sutured. Seven days after surgery, the animals were divided into two equal groups. Group 1 was placed on a 23-h food-deprivation schedule, while Group 2 remained on a free-feeding regimen. Two days later, the mice were paired in a neutral cage (i.e., a cage not inhabitated by either animal). In all cases, littermates of the same group were paired. The animals were kept together for $15 \mathrm{~min}$. A pair of animals was scored as "fight" if one animal lunged at and bit the other. It was}


also noted which animal fought back. Latency to fight was recorded as well.

After 15 min, a 1-g Purina Lab Chow pellet was placed in the center of the cage and subsequent activity recorded for an additional $15 \mathrm{~min}$. Following testing, all mice were returned to isolation. Group 1 was permitted free access to food for 7 days, after which they were paired and observed for aggressive display, as before. Group 2 remained on free feeding for 5 days, succeeded by 2 days of $23-\mathrm{h}$ food deprivation. They were then paired and tested as in the prior trial.

At the termination of testing, all mice were killed and their brains macroscopically examined to determine whether olfactory bulb removal had been complete. Data from pairs of animals which were found to have suffered incomplete bulb removal were discarded. Additional identically treated animals were then added so that each group size would remain at 8 pairs. An independent test for anosmia was not included, since Edwards et al. (1972) have shown that detection of pheromonal stimuli is not necessary for fighting between mice.

The above paradigm offers a somewhat paradoxical situation. Isolating sham-operated male mice, subjecting them to a regimen of food deprivation, then testing for aggression would be the control for the "control" group. However, male mice which are isolated and then paired will engage in spontaneous fighting. It was for this reason that a sham-operate group was felt not feasible and hence not included in this experiment.

\section{Results}

Examination of the brains revealed that all but three animals sustained complete bilateral bulb removal. The pairs which contained these animals were replaced as previously stipulated.

Prior to the presentation of a food pellet, seven of eight pairs in Group 1 exhibited fighting. One pair of this group fought when sated. The difference is statistically significant (binomial test, $N=8, x=1$, $p=.035$ ). None of the eight pairs in Group 2 fought when sated, while six of the eight fought when hungry, prior to pellet presentation. This difference is also statistically significant (binomial test, $\mathrm{N}=8$, $\mathrm{x}=0, \mathrm{p}=.004)$. Pooling the data from Groups 1 and 2 , we see a significant difference between animals fighting when hungry or when not hungry (McNemar test, $\mathrm{x}=6.66, \mathrm{df}=1, \mathrm{p}=.01$ ). Mean latency to attack was $4.3 \mathrm{~min}$ for Group $1,3.9 \mathrm{~min}$ for Group 2. This difference was not significant.

When the behavior of individual animals was analyzed, it was found that one member of a pair invariably was the aggressor. Its behavior typically consisted of the following responses: investigation, rough grooming, chasing, tail-rattling, a lunge, and a bite. The other member of the pair would behave as a typical bulbectomized animal, that is, it would not fight, but rather would assume a submissive posture-rearing upright, forepaws rigidly extended in defense, squeal, freeze, or try to escape from the attack. In the pairs which were scored "no-fight," both members typically ignored each other, as did the nonaggressive pairs when tested following free feeding.

No competitive aggression was observed in hungry animals of either group upon pellet presentation.
Few of the mice found the food pellet despite its being placed on the surface of the wood shavings in the middle of the cage. The mice which found the food (four of the pairs that fought and all of the pairs which did not fight), did so after a considerable period of time, on the order of $8 \mathrm{~min}$. If one member of a pair did find the pellet, the other member either ignored him or sniffed the possessing animal in the facial region, then ignored him. Mice which did not discover the food continued to fight. Typically, the nonaggressive mouse, under continual attack, became totally submissive. At the end of the $1 / 2$-h test, it was noted that three of these submissive animals had part of one or both ears gone, apparently eaten by the attacking member.

The data indicate that neither the presence of food competition conditions nor "territorial" stimuli (testing in a home cage) are necessary for the production of fighting in olfactory bulbectomized male mice. Rather, a state of food deprivation appears sufficient to facilitate aggressive behavior in these animals.

\section{EXPERIMENT 2}

Fredericson (1950) reported that normal male and female mice living together under conditions of food deprivation would not fight until a food pellet was introduced into their cage. The mice in Experiment 1 were housed in isolation until testing. Therefore, the observed fighting may have been, in part, the result of isolation. Experiment 2 sought to investigate this possibility by removing the isolation condition.

\section{Method}

Forty-eight 60-80-day-old Rockland-Swiss albino male mice were divided into two equal groups according to litter. The first group of 24 underwent bilateral olfactory bulb removal. The remaining control animals received sham operations, which consisted of the same procedure as bulb ablation with the exception of aspiration. Immediately following surgery, all animals were paired and housed as described previously. In all cases, littermates were paired. Seven days later, the mice were placed upon 24-h food deprvation. After 2 days of this schedule, pairs were to be observed for fighting. A 2-g Purina Lab Chow pellet was subsequently to be placed into each cage and the behavior noted.

\section{Results}

It was observed without exception that after $23 \mathrm{~h}$ of food deprivation one member of each pair of bulbectomized mice had been eaten (the remains usually consisted of the skeleton and tail). The survivors were then paired and $23 \mathrm{~h}$ later it was again found that one member of each pair had been eaten. Control animals were placed upon terminal deprivation and finally died without one instance of cannabalism. 


\section{DISCUSSION}

The result of these experiments show that, at least for bulectomized mice in the test situation employed above, sufficient condition for the elicitation of aggressive behavior is a food-deprivation state. Thus, Rowe and Edwards' (1971) observation that bulbectomized mice would fight in a food-competition situation may have in actuality been a function of food deprivation rather than by competition per se. A certain discrepancy exists between the data reported here and that of Rowe and Edwards. Few of the animals in Experiment 1 found the food pellet when it was placed into their cage. The fighting which Rowe and Edwards observed was exclusively food directed. This difference may be accounted for by the point at which the pellet was introduced into the cage. In the Rowe and Edwards study, the food pellet was present at the onset of testing. The mice in Experiment 1 did not have access to food until $15 \mathrm{~min}$ of the test session had expired. In the majority of cases, the animals were fighting by this time. It is conceivable that the ongoing fighting behavior overrode noticing the food. The animals were additionally handicapped at finding the food in that they were presumably anosmic.

For descriptive purposes, the type of behavior described here may be subsumed under the rubric "irritable aggression," as delineated by Moyer (1968). Recent evidence suggests that olfactory bulb removal may abolish aggressive behavior, not by eliminating olfactory capability, but by resulting in degeneration to other brain areas (Edwards et al., 1972). If this is true, then the deprivation state can apparently override the debilitating effects of brain damage. Moyer (1968) notes that as drive states are increased, "irritable aggression" is increased. The threshold of arousal, as signaled by EEG recordings, is lowered by depriving cats of food (Kitai \& Morin, 1965) or rats of water (Steiner, 1962). However, the relationship between food deprivation and the neural damage produced by bulbectomy requires further examination in the future. Kuo (1968) has demonstrated with kittens that food deprivation is not a sufficient condition to elicit attack upon mice unless the kitten has previously observed its mother attacking mice.

The observation of Experiment 2 could be interpreted in two ways. First, one member of a bulbectomized pair might have died as a result of the operation and was subsequently eaten by its cagemate. This explanation is unlikely because the survival rate following olfactory bulb removal is at least $90 \%$. A second possibility in consideration of the results of Experiment 1 and 2 is that one number of a bulbectomized pair attacked, killed, and ate the other. It would appear that the aggression noted in
Experiment 1 was preliminary to what would later have been cannibalism if the members had been permanently housed together.

Intraspecific cannabalism is rare and typically involves consumption of the young by adults. Cannibalism of new-born conspecifics in the laboratory has been reported for male and female opossums (Roberts, Steinberg, \& Means, 1967), female hamsters (Noirot \& Richards, 1966), and male and female mice (Davis \& Gandelman, 1972). To our knowledge, only one study had reported cannibalism of adult mice by other adults (Hamilton, 1941), but even here the author indicates that it was impossible to tell if the victims were found dead and eaten or were killed by conspecifics. None of the 12 pairs of littermate sham-operates in Experiment 2 engaged in cannibalism, in spite of being starved. This fits well with Kuo's (1966) observation that food deprivation will not alter the established food habits of cats, dogs, or birds.

Although spontaneous pup killing among male and female mice is rare, the response can be reliably elicited by removing the olfactory bulbs (Gandelman, Zarrow, Denenberg, \& Meyers, 1971). A wide variety of other social behaviors, such as intraspecific aggression (Ropartz, 1968), mating (Thompson \& Edwards, 1972), and behavioral thermoregulation (Edwards \& Roberts, 1973), are severely attenuated by bulbectomy. The experiments reported here indicate that the condition of food deprivation is sufficient to: (1) reinstate intraspecific aggression in bulbectomized mice, and (2) combine with the effects of bulbectomy to promote normally inhibited cannibalism. It was not considered within the scope of the experiments reported here to closely scrutinize the effects of food deprivation per se on aggression. The investigation of this area, as well as its interaction with bulbectomy, might be a profitable area for future research.

\section{REFERENCES}

ARChER, J. The effect of strange odor on aggressive behavior in male mice. Journal of Mammalogy, 1968, 49, 572-575.

CoNNER, J. Olfactory control of aggressive and sexual behavior in the mouse (Mus musculus L.). Psychonomic Science, 1972, 27, 1-4.

Davis, P. G., \& Gandelman, R. Pup killing produced by administration of testosterone propionate to adult female mice. Hormones and Behavior, 1972, 3, 169-173.

Denenberg, V. H., Gaulin-Kremer, E., Gandelman, R., \& Zarrow, M. X. The development of standard stimulus animals for mouse (Mus musculus) aggression testing by means of olfactory bulbectomy. Animal Behaviour, 1973, 21, 590-598.

Edwards, D. A., Thompson, M. L., \& Burge, K. G. Olfactory bulb removal vs. peripherally induced anosmia. Differential effects on the aggressive behavior of male mice. Behavioral Bioloby, 1972, 7, 823-828.

EDwards, D. A., \& Roberts, R. L. Olfactory bulb removal produces a selective deficit in behavioral thermoregulation. Physiology and Behavior, 1973, 9, 747-752. 
Fortuna, M., \& Gandelman, R. Elimination of pain-induced aggression in male mice following olfactory bulb removal. Physiology and Behavior, 1972, 9, 397-400.

Fredericson, E. The effects of food deprivation upon competitive and spontaneous combat in c57 Black mice. Journal of Psychology, 1950, 29, 89-100.

Gandelman, R., Zarrow, M. X., Denenberg, V. H., \& MEYeRs, M. Olfactory bulb removal eliminates maternal behavior in the mouse. Science, 1971, 171, 210-211.

Hamilton, J. W. The food of small forest mammals in eastern United States. Journal of Mammalogy, 1941, 22, 250-263.

Kitai, S. T., \& Morin, F. Cortical evoked potentials and appetitive drive. Nature (Lond.), 1965, 206, 1375.

Kuo, Z. Y. The dynamics of behavior development: An epigenetic view. New York: Random House, 1968.

MOYER, K. E. Kinds of aggression and their physiological basis. Communications in Behavioral Biology, 1968, 2, 65-87.

Mugford, R. A., \& Nowell, N. W. Pheromones and their effect on aggression in mice. Nature, 1970, 226, 967-968.

Mugford, R. A., \& Nowell, N. W. Endocrine control over production and activity of the anti-aggression pheromone from female mice. Journal of Endocrinology, 1971, 49, 225-232.

NoIRot, E., \& RichaRds, M. P. M. Maternal behavior in virgin female golden hamsters: Changes consequent upon initial contact with pups. Animal Behaviour, 1966, 14, 7-10.

Roberts, W. W., Steinberg, M. L., \& Means, L. W. Hypothalamic mechanisms for sexual, aggressive, and other motivational behaviors in the opossum, Didephus virginiand. Journal of Comparative and Physiological Psychology, 1967, 64, 1-15.

RoparTz, P. The relation between olfactory stimulation and aggressive behavior in mice. Animal Behaviour, 1968, 16, 97-100.

Rowe, F. A., \& EDwards, D. A. Olfactory bulb removal: Influences on the aggressive behaviors of male mice. Physiology and Behavior, 1971, 7, 889-892.

STEINER, W. G. Electrical activity of rat brain as a correlate of primary drive. Electroencephalography and Clinical Neurophysiology, 1962, 14, 223.

Thompson, M. L., \& Edwards, D. A. Olfactory bulb removal impairs the hormonal induction of sexual receptivity in spayed female mice. Physiology and Behavior, 1972, 8, 1141-1146.

(Received for publication February 28, 1977; accepted April 28, 1977.) 